\title{
Evaluation of the Synergistic Effect of Erosion-Corrosion on AISI 4330 Steel in Saline-Sand Multiphase Flow by Electrochemical and Gravimetric Techniques
}

\author{
Dario Yesid Peña Ballesteros, Yelsin Enrique Mendez Camacho, \\ and Lizeth Viviana Barreto Hernandez \\ Grupo de Investigaciones en Corrosión (GIC), Metallurgical Engineering and Materials Science School, Parque Tecnológico Guatiguará, \\ Universidad Industrial de Santander, Bucaramanga, Colombia \\ Correspondence should be addressed to Dario Yesid Peña Ballesteros; darioypb@gmail.com
}

Received 29 October 2015; Revised 16 February 2016; Accepted 24 April 2016

Academic Editor: Shengshui $\mathrm{Hu}$

Copyright (C) 2016 Dario Yesid Peña Ballesteros et al. This is an open access article distributed under the Creative Commons Attribution License, which permits unrestricted use, distribution, and reproduction in any medium, provided the original work is properly cited.

\begin{abstract}
The synergistic effects of fluid flow, sand particles, and solution $\mathrm{pH}$ on erosion-corrosion of AISI 4330 steel alloy in saline-sand medium were studied through a rotating cylinder electrode (RCE) system by weight-loss and electrochemical measurements. The worn surface was analyzed by X-ray diffraction (XRD) and scanning electron microscopy (SEM). Results show that, under all the test conditions assessed, the passivity of the steel alloy could not be maintained; as a result, an activation mechanism dominates the corrosion process of steel alloy. Furthermore, the potentiodynamic curves show that, with the increasing of the electrode flow rate and particle size, the anodic current density increased, which is due to deterioration of the electrode by the impacting slurry. Although the increase of particle size affects the anodic current density, the effect of particle size does not cause a significant change in the polarization behavior of the steel electrode. The electrochemical impedance and potentiodynamic curves suggest that erosioncorrosion phenomenon of the ASISI 4330 steel is under mixed control of mass transport and charge transfer. The inductive loops formed in the impedance plots are representative of an increase in roughness of the electrode caused by the particles impacting at the surface. The change in the passivity of the steel alloy as the $\mathrm{pH}$ is altered plays an important role in the corrosion rate.
\end{abstract}

\section{Introduction}

Erosion-corrosion is the metal deterioration that involves mechanical wear by impacting solid particles at the metal surface in conjunction with electrochemical dissolution of the metal by the corrosive solution, with both activities occurring synergistically in a dynamic two-phase fluid [1]. Sand presence in production fluids raises new challenges for project development and subsequent operations. Since practical piping systems operate in turbulent flow conditions, the damage to the interior pipe walls can be large, resulting in unexpected shut down of the line when sand enters into the production line. It is universally acknowledged that erosioncorrosion damage might be alleviated by the formation of a passive film on the metal/alloy surface. Protection by this film is limited to environments in which the oxide film is highly soluble [2]. PH condition has a great effect in the stability of these films which is consistent with the Pourbaix diagram [3]. Formation, stability, damage, and repairing of the passive film are some of the major topics of fundamental erosioncorrosion research.

Some researchers [4] focused on the correlations between the synergistic effect of erosion-corrosion and the impact energy associated to the fluid flow velocity. The impact energy has dual effects. On one hand, it destroys the passive film. On the other hand, it attacks the metal substrate, causing a significant increase in mass loss. The resulting mass loss caused by the synergism of erosion-corrosion in slurrytransport system is higher than the sum of the erosion rate in the inert environment and the corrosion rate under the erosion-free condition $[5,6]$. Two mechanisms have been proposed for illustration of the synergism [7]. Erosion may 
enhance the corrosion rate by removal of the passive film and exposing the metal surface to the corrosive medium (electrolyte). If the metal is unable to repassivate, then there will be appreciable corrosion rate [8]. Corrosion may enhance erosion as the particle impacts the passive film and damages it, dissolution of the surface leads to the elimination of the work hardened layer and increases the surface roughness. $\mathrm{Li}$ et al. [9] suggested another possible mechanism on how corrosion can enhance erosion, through localized attack at sites where the passive layer is ruptured during impact, leading to an increase in the electrochemical activity of these sites. In addition to the suggested mechanisms provided for the effect of corrosion on erosion, Mohammadi and Luo [10] proposed that if a passive metal is held in the passive potential range, the repassivation rate of the metal surface will be much more than the rate of metallic dissolution. Therefore, the material would be more resistant to erosion phenomenon.

Another study by Clark [11] pointed that the increase in the particle size will result in a greater impact kinetic energy. Consequently, this will lead to a higher corrosion rate. However, as the particles become larger, the total number of particles impacting the surface will decrease for a given constant concentration defined by mass. Before impacting the electrode surface, particles may collide with each other, causing the screening effect, thus, leading to lower erosion rates [12]. Therefore, there would be a threshold particle size at which this effect would be most pronounced. Furthermore, it has been reported [7] that, below a critical size value, particles' entrapment at the metal surface increases considerably and the relationship of particle impact energy is no longer valid.

Weight-loss measurements and electrochemical tests were applied in this study to determinate the synergistic effect of erosion-corrosion phenomenon in an AISI SAE 4330 steel electrode. Measurements of potentiodynamic polarization, electrochemical impedance spectroscopy (EIS), and corrosion rate by linear polarization $\left(R_{p}\right)$, combined with SEM and XRD analysis, were used to develop a better understanding of the synergistic effect. A rotating disk electrode system was used to control the rotation speed of the electrolyte. The influence of electrode rotating rate, erodent size, and $\mathrm{pH}$ were investigated to determine the roles of each parameter in the erosion-corrosion damage of an AISI SAE 4330 steel electrode.

\section{Experimental}

2.1. Materials and Solutions. The rotating disk working electrode was made of 4330 steel alloy with the chemical composition (wt, \%): $\mathrm{Cu} 0.20, \mathrm{Al} 0.03, \mathrm{~V} 0.06, \mathrm{Cr} 0.8$, Ni 1.7, Si 0.30, Mn 0.80, P 0.01, C 0.3, and Fe balance. The shape of the specimens was cylindrical with a working area of $3 \mathrm{~cm}^{2}$. Their microstructures all consist of tempered martensite as it is shown in Figure 1; these tempering conditions produced scattered carbide precipitates. These carbides arise during tempering heat treatment, which is performed subsequent to quenching. Before the commencement of tests, the work surfaces of samples were ground with silicon carbide abrasive paper up to 1000 grits and degreased by immersion in acetone

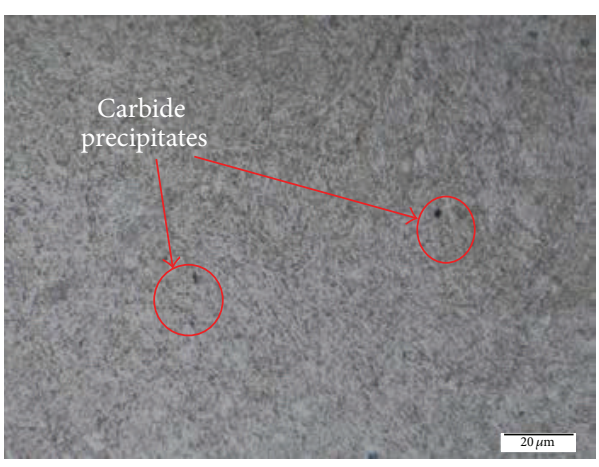

FIGURE 1: Microstructure of quenched and tempered AISI 4330 steel electrode, magnification 1000x.

in an ultrasonic bath, rinsed with deionized water, and then dried and stored in a desiccator.

Tests were conducted in 1L solution containing $3 \mathrm{wt} . \%$ $\mathrm{NaCl}$ with a constant concentration of $10 \mathrm{wt} . \%$ silica particles in deionized water. To investigate the effect of the erodent on the steel corrosion, the experiments were conducted at two velocities (1800-2800 rpm) and two diameters (53-105 $\mu \mathrm{m})$. The experiments were carried out in two different $\mathrm{pH}$ values (3-7). The $\mathrm{pH}$ of the solution was adjusted using $\mathrm{HCl}$ or $\mathrm{NaOH}$. All the tests were performed at ambient temperature $\left(\sim 25^{\circ} \mathrm{C}\right)$ and with the medium exposed to air.

2.2. Electrochemical Measurements. Electrochemical measurements were conducted through a RCE system on a threeelectrode test cell, with AISI SAE 4330 steel electrode as working electrode (WE), an AISI 316 stainless steel rod as counter electrode (CE), and a saturated calomel electrode (SCE) as reference electrode (RE). The saturated calomel electrode was connected to the cell via a Luggin probe. The configurations of WE, CE, and RE are shown in Figure 2.

During the open-circuit potential test, samples were immersed in solution for $40 \mathrm{~min}$ to attain the corrosion potential. Then, EIS started and lasted for $40 \mathrm{~min}$. EIS measurements were carried out using a sinusoidal potential perturbation of $10 \mathrm{mV}$ in a frequency ranging from $10000 \mathrm{~Hz}$ to $0.01 \mathrm{~Hz}$. This was followed by $R_{p}$ during $10 \mathrm{~min}$ to determine the instantaneous corrosion rate after $90 \mathrm{~min}$ of test. $R_{p}$ was measured by polarizing the specimen $\pm 10 \mathrm{mV}$. Finally, the potentiodynamic polarization curves were swept from -1000 to $+800 \mathrm{mV}$ according to corrosion potential at a fixed rate of $1 \mathrm{mV} / \mathrm{s}$. Note that at least two tests with identical conditions were carried out.

2.3. Surface Characterization. After tests, steel alloy electrodes were rinsed with deionized water. The surface morphologies were observed and analyzed by SEM, and the specific iron oxide compounds formed on the electrode surface were identified by XRD.

2.4. Weight-Loss Measurements. Mass loss measurements were made only in samples not submitted to application of an external potential (e.g., samples that were not connected 


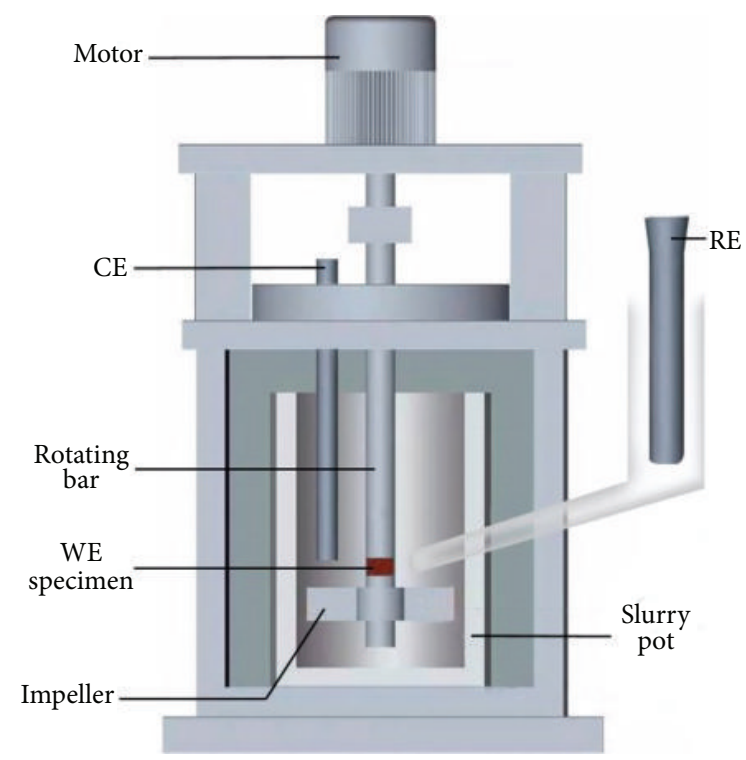

Figure 2: Schematic diagram of the modified erosion-corrosion apparatus.

to the potentiostat). To compare the corrosion rate from mass loss values with the instantaneous corrosion rate determined by $R_{p}$, all these specimens were tested for $90 \mathrm{~min}$. After weight-loss measurements, the oxide film formed on electrode surface was cautiously removed with a descaling solution. The removal of corrosion products was carried out following the procedures established by the ASTM G1-03 standard [13]. Then, the weight of the electrode was measured using an electronic balance with a precision of $0.1 \mathrm{mg}$.

\section{Results and Discussion}

3.1. Synergistic Effect of Fluid Flow Velocity and $p H$ on Corrosion of 4330 Steel Alloy. Figure 3 shows capacitive semicircles in the high frequency range and inductive loops in the low frequency range for Nyquist plots. The EIS plots indicate that charge-transfer resistance $\left(R_{\mathrm{ct}}\right)$, which is a characteristic magnitude for current flowing through electrochemical reactions that occur at the electrode surface, is determined by the diameter of the capacitive semicircle [14]. It is seen that the capacitive semicircles under static conditions were much larger than those measured under flow condition. With the increase of flow velocity and acidification of the electrolyte, the diameter of the capacitive semicircles decreased. Therefore, $R_{\mathrm{ct}}$ decreases continuously with the increasing flow velocity and acidification of the solution. Corrosion related to electrochemical reactions at the metal/flowing-electrolyte interface and erosion related to particle impact will be enhanced as a result of the increment of rotation speed and acidification of the electrolyte. The influence of fluid hydrodynamics and sand particles on erosion-corrosion phenomenon is directly correlated with the chemical and physical characteristics of the oxide film, which varies according to solution $\mathrm{pH}$; this means that $\mathrm{pH}$ normally influences the corrosion behavior of steel alloys

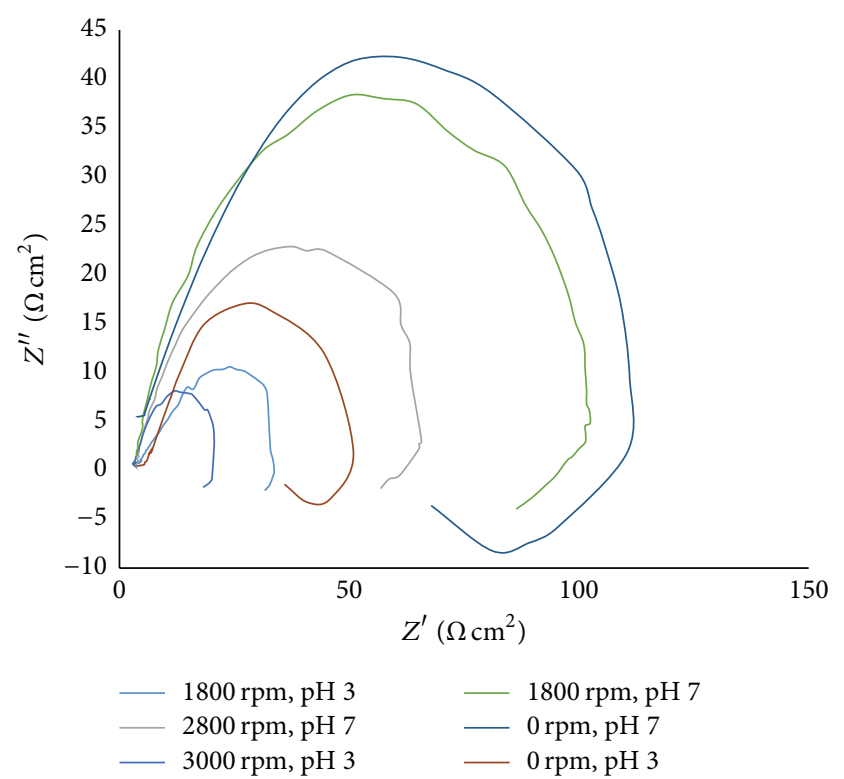

FIgURE 3: Nyquist diagrams of AISI 4330 steel electrode at the various $\mathrm{pH}$ solutions and rotating speeds in solutions containing $3 \mathrm{wt} . \% \mathrm{NaCl}$ with a constant concentration of $10 \mathrm{wt} . \%$ silica particles $(105 \mu \mathrm{m})$.

by changing the stability of the oxide films $[2,3]$. In acidic environments, the oxide film is highly soluble and this leads to higher corrosion rates. Another factor, which enhances corrosion at $\mathrm{pH} 3$, is the acceleration of the cathodic reaction, due to the high concentration of $\mathrm{H}^{+}$ions [2].

To further determine the effect of sand particles on destabilization of the electrode, measurements of potentiodynamic polarization curves were done (see Figure 4). It is seen that corrosion potential drops instantaneously as a result of impacting sand particles and increase of fluid flow velocity. It is well known that corrosion potential is an indicator of corrosion activity and not a measurement of corrosion rate. The significant drop in corrosion potential under dynamic conditions and addition of sand particles is directly associated to the electrode destabilization. Moreover, it is also seen that, with the increase of electrode rotation speed and acidification of the solution, both anodic and cathodic current densities increased considerably. The increasing fluid rotation rate makes the oxygen diffusion be accelerated, which is indicated by an increment in the cathodic current density. At the same time that the current density is increasing because of the increasing fluid rotation velocity, the impact energy of sand particles is increased, which is indicated by an increment in the anodic current density. Furthermore, the electrolyte acidic condition tends to accelerate the dissolution of the metal, increasing the electrode corrosion rate.

\subsection{Synergistic Effects of Fluid Flow Velocity and Sand Particles} Size on Corrosion of 4330 Steel Alloy Electrode. Figure 5 Shows the Nyquist curves of 4330 steel alloy electrode at the various rotating speeds and particle sizes in solution containing $10 \mathrm{wt}$.\% silica particles. It is seen that all the EIS 


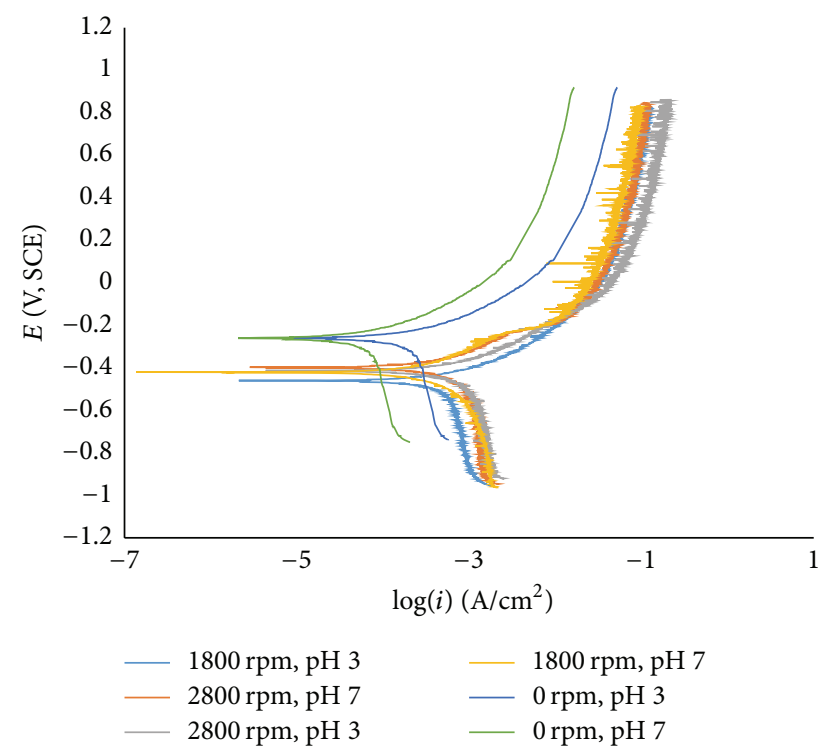

FIGURE 4: Potentiodynamic polarization curves of AISI 4330 steel electrode at the various $\mathrm{pH}$ solutions and rotating speeds in solutions containing $3 \mathrm{wt} . \% \mathrm{NaCl}$ with a constant concentration of $10 \mathrm{wt} . \%$ silica particles $(105 \mu \mathrm{m})$.

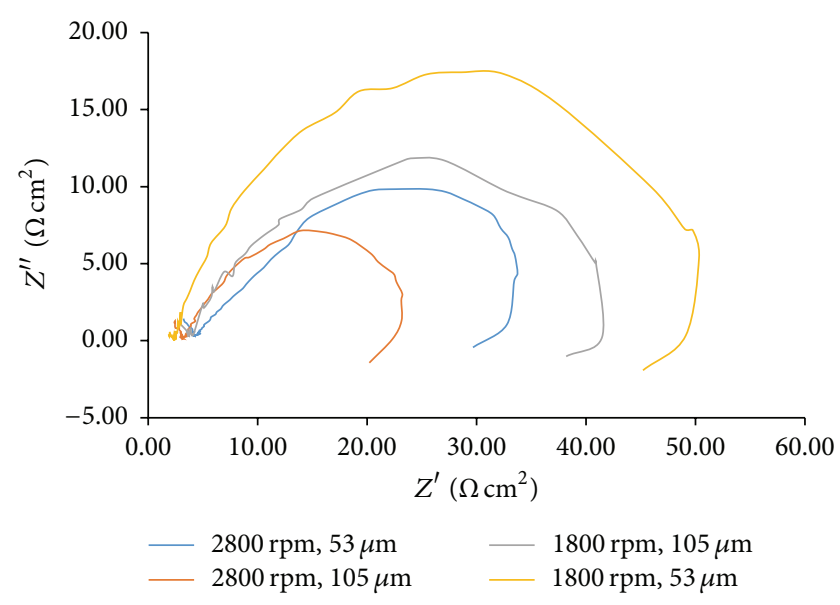

FIGURE 5: Nyquist diagrams of AISI 4330 steel electrode at different rotating speeds and particle sizes in $\mathrm{pH} 3$ solutions containing $3 \mathrm{wt} . \%$ $\mathrm{NaCl}$ with a constant concentration of $10 \mathrm{wt} . \%$ silica particles in deionized water.

curves in the high frequency range show depressed semicircles and in the low frequency range show the formation of inductive loops. Additionally, the value of $R_{\mathrm{ct}}$ which is indicated by the diameter of the semicircles decreased with the increasing particle size and electrode rotation speed. The kinetic energy of the impinging particle is directly proportional to the speed [15]. In general, at elevated rotation speeds, the attack will be more severe, due to the greater kinetic energy of sands impacting the electrode and the higher number of sands reaching the electrode surface $[15$, 16]. Moreover, it is demonstrated that the striking efficiency is directly proportional to particle size. Lynn et al. [17] found that the severity of erosive attack is dependent on the particle

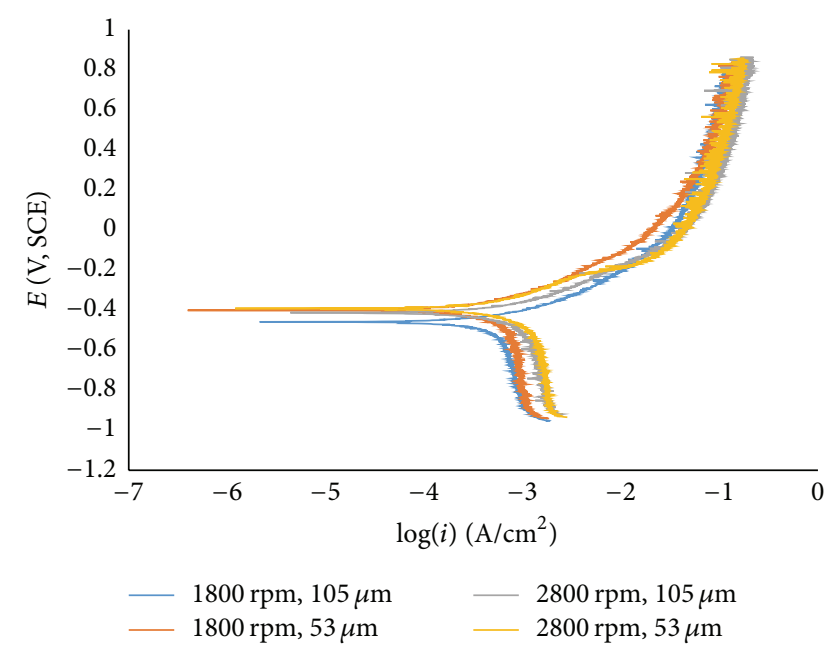

FIGURE 6: Potentiodynamic polarization curves of AISI 4330 steel electrode at different rotating speeds and particle sizes in $\mathrm{pH} 3$ solutions containing $3 \mathrm{wt} . \% \mathrm{NaCl}$ with a constant concentration of $10 \mathrm{wt} . \%$ silica particles in deionized water.

size; big sand particles have higher striking efficiency and dissipate greater kinetic energy during impact, causing more wear. Commonly, roughness at the electrode surface caused by particles impact generates the formation of inductive loops in the low frequency range for EIS plots [18]. Even though surface adsorption is considered another factor which could generate inductive loops in the low frequency range in EIS plots, it is evident that not any adsorption occurs in the present system [19].

Figure 6 shows the polarization curves measured on the steel electrode as a function of rotation speed and particle size. The increasing fluid rotation speed would enhance the diffusion of dissolved oxygen towards the electrode surface, accelerating the cathodic reduction reaction. Therefore, the electrode oxidation is increased due to the large supplement of oxidant $[18,19]$. At the same time that the oxidation of the steel electrode is enhanced with the further increase of fluid velocity, the erosive attack of sands contained in the electrolyte is enhanced considerably. Therefore, heterogeneity of the oxide layer, exposure of fresh metal to the corrosive solution, and destabilization of the electrode take place, which is demonstrated by an increasing anodic current density. Hence, there will be competition between oxidation and activation phenomenon of the steel electrode immersed in the solution. Moreover, it is well known that the anodic current density increases with the sand particle size, due to the larger kinetic energy of bigger sand particles that impact the electrode surface. This impact kinetic energy depends on two factors, mass of the particles and fluid flow velocity. Thus, larger particles cause more severe attack because they have greater mass.

Another conclusion derived from the polarization curves (Figures 4 and 6) is the active dissolution mechanism without any distinctive transition to passivation starting from $-0.4 \mathrm{~V} / \mathrm{SCE}$, indicating a constant dissolution behavior and rupture of oxides formed on the steel surface, due to the 
TABLE 1: Values of the elements that integrate the equivalent circuit.

\begin{tabular}{|c|c|c|c|c|c|c|}
\hline Tests & $R_{1}(\Omega)$ & $\mathrm{CPE}(F) \times 10^{-3}$ & $n$ & $R_{2}(\Omega)$ & $R_{3}(\Omega)$ & $L$ \\
\hline $1800 \mathrm{rpm}, \mathrm{pH} 3,105 \mu \mathrm{m}$ & 3.976 & 3.13 & 0.478 & 70.71 & 58.2 & 709.7 \\
\hline $1800 \mathrm{rpm}, \mathrm{pH} 3,53 \mu \mathrm{m}$ & 3.908 & 2.83 & 0.54223 & 81.93 & 59.71 & 712.5 \\
\hline $1800 \mathrm{rpm}, \mathrm{pH} 7,53 \mu \mathrm{m}$ & 3.058 & 3.47 & 0.79362 & 160.59 & 64.34 & 725.4 \\
\hline $1800 \mathrm{rpm}, \mathrm{pH} 7,105 \mu \mathrm{m}$ & 3.131 & 4.5 & 0.75769 & 153.59 & 63.2 & 720.74 \\
\hline $2800 \mathrm{rpm}, \mathrm{pH} 3,105 \mu \mathrm{m}$ & 3.179 & 3.59 & 0.45986 & 42.4 & 42.42 & 452.3 \\
\hline $2800 \mathrm{rpm}, \mathrm{pH} 3,53 \mu \mathrm{m}$ & 2.329 & 2.98 & 0.47319 & 49.46 & 47.9 & 475.2 \\
\hline $2800 \mathrm{rpm}, \mathrm{pH} 7,53 \mu \mathrm{m}$ & 3.621 & 0.92 & 0.75074 & 171.56 & 62.81 & 719.4 \\
\hline $2800 \mathrm{rpm}, \mathrm{pH} 7,105 \mu \mathrm{m}$ & 3.341 & 0.66 & 0.71109 & 159.9 & 61.2 & 717.25 \\
\hline
\end{tabular}

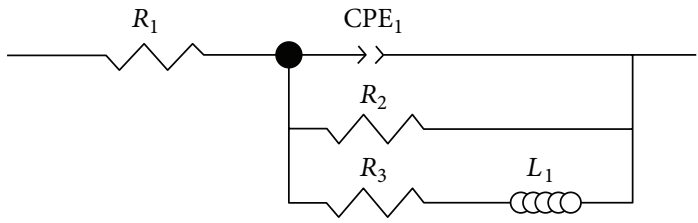

FIGURE 7: Electrochemical equivalent circuit of the EIS results measured.

presence of chlorides and the successive impact of particles on the electrode surface that destroy and weaken formation of corrosion products on the steel surface. Finally, although the cathodic current approaches to diffusion limited current, the electrode corrosion processes cannot be controlled by pure diffusion due to the fact that Nyquist plots did not show a Warburg behavior in the low frequencies range; therefore, it is logical to sum up that the steel electrode is controlled by diffusion and activation processes, that is, mixed controlled.

Figure 7 shows the equivalent circuit related to the Nyquist plots. The equivalent circuit consists of a resistor in series with a parallel combination of a constant phase element $(\mathrm{CPE})$, a resistor, and a series combination of a resistor and an inductor. Zhang et al. [18] provided a physical description for each element in the circuit as follows: $R_{1}$ represents the electrolyte resistance, $\mathrm{CPE}_{1}$ is related to the ionic species transport across the film and/or film/electrolyte interface, $R_{2}$ stands for the charge transfer resistance at the interface film/electrolyte, and $R_{3}$ and $L_{1}$ represent the inductance resistance and inductance.

A constant phase element (CPE) is introduced in the equivalent circuit to model the response of a nonhomogeneous system, such as the surface roughness of the steel electrode [20]. CPE has two constant parameters, $Y_{0}$ and $n$, and the impedance of element is given by the following formula [19]:

$$
Z_{\mathrm{CPE}}=\frac{(j \omega)^{-n}}{Y_{0}}
$$

where $\omega$ is the angular frequency. Generally, $0<n<1$, when $n=1$, and the CPE describes an ideal capacitor corresponding to the conventional double layer capacitance, and it behaves like a resistor for $n=0$. The values of elements associated to the equivalent circuit are listed in

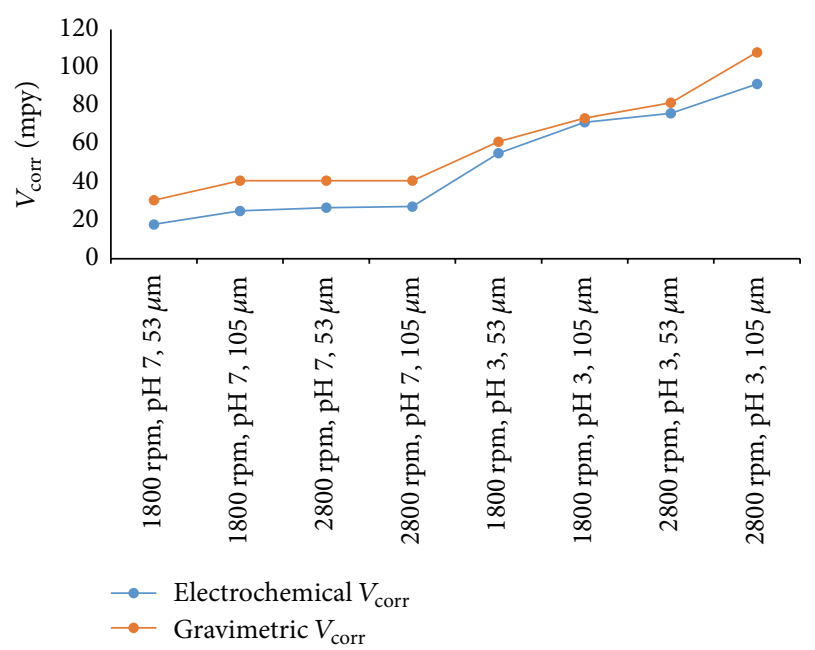

Figure 8: Corrosion rates of AISI 4330 electrode under impingement by $\mathrm{NaCl}$ solution containing $10 \mathrm{wt}$.\% sand at different flow velocities, particle sizes, and $\mathrm{pH}$ values.

Table 1. An accelerated corrosion decreases charge transfer resistance $\left(R_{2}\right)$ and increases surface roughness. Hence, both $R_{2}$ and $n$ decrease simultaneously at low $\mathrm{pH}$ and with the increase of flow velocity and particle size. Moreover, it is seen that, with the increase of rotation speed and particle size, the inductance and inductance resistance decreased, representing an increasing surface activity of electrode upon the enhanced impingement of sands. Based on the values of $R_{2}$, it is seen that the influence of particle size does not have a remarkable effect on the electrode polarization. In general, one of the factors that influence the deterioration by erosion phenomenon is directly related to sand particle size, which depends on two aspects: as a first step, larger particles cause more severe damage due to their greater mass. As a second step, large particle could begin to collide among themselves; therefore, there will be lower frequency of particles impacting the electrode surface. Since these two aspects offset each other, a remarkable effect of particles size on the polarization behavior is not expected.

3.3. Gravimetric Analysis. In Figure 8, it is apparent that the electrode suffers from a smaller corrosion rate at $\mathrm{pH} 7$ conditions than at $\mathrm{pH} 3$, indicating that the erosion-corrosion 


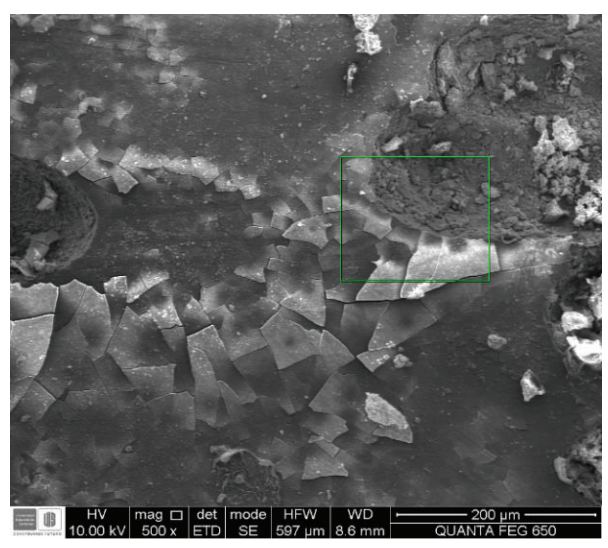

(a)

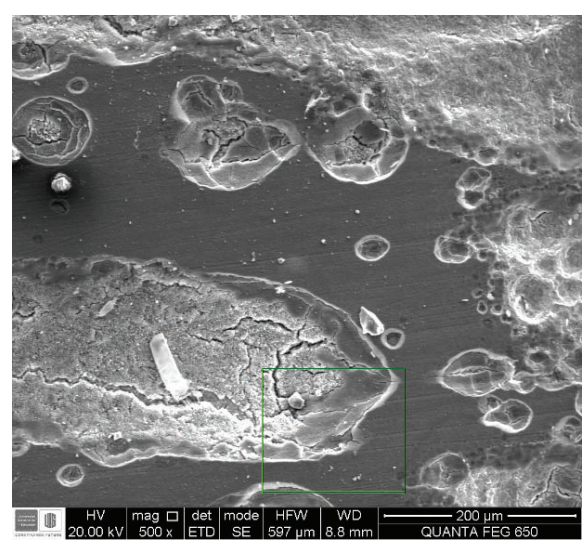

(b)

FIGURE 9: SEM images of AISI 4330 steel electrode after tests in a solution containing $3 \mathrm{wt} . \% \mathrm{NaCl}$ and $10 \mathrm{wt} . \% \mathrm{sand}$ (a) $2800 \mathrm{rpm}$, pH 7 , $105 \mu \mathrm{m}$ and (b) $1800 \mathrm{rpm}, \mathrm{pH} 3,53 \mu \mathrm{m}$, magnification 500x.

resistance of the electrode is highly affected in acidic solutions. As a general trend, the corrosion rate increases with the flow velocity, particle size, and acid medium in both curves, although the synergistic effect of these variables is hardly appreciable in the tests at $\mathrm{pH}$ 7. Based on this, $\mathrm{pH}$ 3 can be defined as the critical variable due to the fact that corrosion rate increases rapidly with the influence of flow velocity and particle size. The high impact of these parameters in the erosion-corrosion rate of the electrode in low $\mathrm{pH}$ environments is attributed to the reduction of the work hardened layer (through dissolution) leaving the substrate more vulnerable to mechanical attack $[7,21]$.

\subsection{Microscopic Characterization of Electrodes after Impinge-} ment Tests. Figures 9(a) and 9(b) show the SEM surface morphologies of the specimens exposed to erosioncorrosion tests with magnifications of 500x. It is observed that holes and craters were formed along the electrode surface in both micrographs. In Figure 9(a), the formation of a corrosion-product layer of $\mathrm{Fe}_{3} \mathrm{O}_{4}$ is shown, determined by XRD (see Supplementary Material available online at http://dx.doi.org/10.1155/2016/1831654), which would create an additional barrier to diffusion, while at $\mathrm{pH} 3.0$ (Figure $9(\mathrm{~b})$ ), the oxide dissolves as it is formed rather than depositing on the metal surface to form a film. Hence, XRD was applied to the sand finding $\mathrm{Fe}_{2} \mathrm{O}_{3}$ under $\mathrm{pH} 3$ conditions (see Supplementary Material). Finally, the increased solubility of iron under $\mathrm{pH} 3$ conditions would tend to expose the metal to the presence of chlorides, hydrogen ions, and particles impact, making the corrosion reaction proceeds at a greater rate than it does at $\mathrm{pH} 7$ conditions.

\section{Conclusions}

The enhanced impact kinetic energy of sand particles due to high rotational speeds of the fluid and larger sand particles causes the destabilization of electrode and, therefore, the increase in the anodic current density. There is no significant influence on the polarization behavior of the AISI SAE 4330 electrode, when the particles become larger.

Impingement by sand containing $\mathrm{NaCl}$ solution under neutral $\mathrm{pH}$ conditions has very little impact on the erosioncorrosion damage of the steel alloy, while, at acidic $\mathrm{pH}$ condition, corrosion rate increases rapidly with the flow velocity and particle size, defining it as the critical variable in the deterioration by erosion-corrosion of steel.

From the polarization curves, it is comprehensible that the passivity of the AISI SAE 4330 electrode could not be kept under any test condition, indicating that an activation mechanism controls the corrosion process of the electrode.

The enhanced roughness of electrode caused by the sand particles impact is indicated by the presence of inductive loop in EIS measurements. The electrode processes occurring on the steel alloy are mixed-controlled by both activation and diffusion steps at all studied conditions.

\section{Competing Interests}

The authors declare that they have no competing interests.

\section{Acknowledgments}

This work was supported by Grupo de Investigaciones en Corrosión (GIC), Parque Tecnológico Guatiguará, Universidad Industrial de Santander.

\section{References}

[1] J. Malik, I. H. Toor, W. H. Ahmed et al., "Investigations on the corrosion-enhanced erosion behavior of carbon steel AISI SAE 1020," International Journal of Electrochemical Science, vol. 9, pp. 6765-6780, 2014.

[2] R. Ambat and E. S. Dwarakadasa, "Studies on the influence of chloride ion and $\mathrm{pH}$ on the electrochemical behaviour of aluminium alloys 8090 and 2014," Journal of Applied Electrochemistry, vol. 24, no. 9, pp. 911-916, 1994. 
[3] M. M. Stack and N. Pungwiwat, "Particulate erosion-corrosion of $\mathrm{Al}$ in aqueous conditions: some perspectives on $\mathrm{pH}$ effects on the erosion-corrosion map," Tribology International, vol. 35, no. 10, pp. 651-660, 2002.

[4] Z. B. Zheng, Y. G. Zheng, X. Zhou, S. Y. He, W. H. Sun, and J. Q. Wang, "Determination of the critical flow velocities for erosion-corrosion of passive materials under impingement by $\mathrm{NaCl}$ solution containing sand," Corrosion Science, vol. 88, pp. 187-196, 2014.

[5] B. T. Lu, J. F. Lu, and J. L. Luo, "Erosion-corrosion of carbon steel in simulated tailing slurries," Corrosion Science, vol. 53, no. 3, pp. 1000-1008, 2011.

[6] Z. Guanghong, D. Hongyan, Z. Yue, and L. Nianlian, "Corrosion-erosion wear behaviors of $13 \mathrm{Cr} 24 \mathrm{Mn} 0.44 \mathrm{~N}$ stainless steel in saline-sand slurry," Tribology International, vol. 43, no. 5-6, pp. 891-896, 2010.

[7] S. S. Rajahram, Erosion-Corrosion Mechanisms of Stainless Steel UNS S31603, School of Engineering Sciences, Faculty of Engineering, Science and Mathematics, University of Southampton, Southampton, UK, 2010.

[8] C. T. Liu and J. K. Wu, "Influence of $\mathrm{pH}$ on the passivation behavior of $254 \mathrm{SMO}$ stainless steel in $3.5 \% \mathrm{NaCl}$ solution," Corrosion Science, vol. 49, no. 5, pp. 2198-2209, 2007.

[9] Y. Li, G. T. Burstein, and I. M. Hutchings, "The influence of corrosion on the erosion of aluminium by aqueous silica slurries," Wear, vol. 186-187, no. 2, pp. 515-522, 1995.

[10] F. Mohammadi and J. Luo, "Effects of particle angular velocity and friction force on erosion enhanced corrosion of 304 stainless steel," Corrosion Science, vol. 52, no. 9, pp. 2994-3001, 2010.

[11] H. M. Clark, "Particle velocity and size effects in laboratory slurry erosion measurements OR... do you know what your particles are doing?" Tribology International, vol. 35, no. 10, pp. 617-624, 2002.

[12] C. G. Telfer, M. M. Stack, and B. D. Jana, "Particle concentration and size effects on the erosion-corrosion of pure metals in aqueous slurries," Tribology International, vol. 53, pp. 35-44, 2012.

[13] American Society for Testing and Materials-ASTM, "Standard practice for preparing, cleaning, and evaluating corrosion test specimens," ASTM G1-03, ASTM, West Conshohocken, Pa, USA, 2002.

[14] D. A. Jones, Principles and Prevention of Corrosion, Department of Chemical and Metallurgical Engineering, University of Nevada, Reno, Nev, USA, 2nd edition, 1996.

[15] S. Das, Y. L. Saraswathi, and D. P. Mondal, "Erosive-corrosive wear of aluminum alloy composites: influence of slurry composition and speed," Wear, vol. 261, no. 2, pp. 180-190, 2006.

[16] G. T. Burstein and K. Sasaki, "Detecting electrochemical transients generated by erosion-corrosion," Electrochimica Acta, vol. 46, no. 24-25, pp. 3675-3683, 2001.

[17] R. S. Lynn, K. K. Wong, and H. M. Clark, "On the particle size effect in slurry erosion," Wear, vol. 149, no. 1-2, pp. 55-71, 1991.

[18] G. A. Zhang, L. Y. Xu, and Y. F. Cheng, "Investigation of erosioncorrosion of 3003 aluminum alloy in ethylene glycol-water solution by impingement jet system," Corrosion Science, vol. 51, no. 2, pp. 283-290, 2009.

[19] L. Niu and Y. F. Cheng, "Synergistic effects of fluid flow and sand particles on erosion-corrosion of aluminum in ethylene glycolwater solutions," Wear, vol. 265, no. 3-4, pp. 367-374, 2008.
[20] N. Mahato and M. M. Singh, "Investigation of passive film properties and pitting resistance of AISI 316 in aqueous ethanoic acid containing chloride ions using electrochemical impedance spectroscopy(EIS)," Portugaliae Electrochimica Acta, vol. 29, no. 4, pp. 233-251, 2011.

[21] M. M. Stack, N. Corlett, and S. Turgoose, "Some recent advances in the development of theoretical approaches for the construction of erosion-corrosion maps in aqueous conditions," Wear, vol. 233-235, pp. 535-541, 1999. 

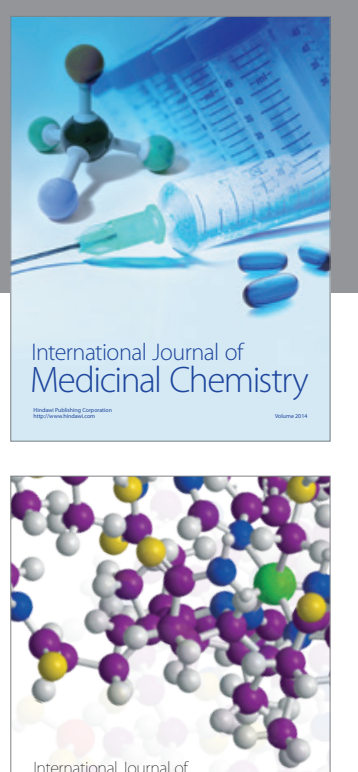

Carbohydrate Chemistry

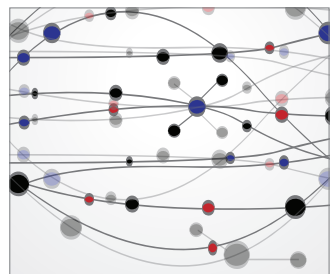

The Scientific World Journal
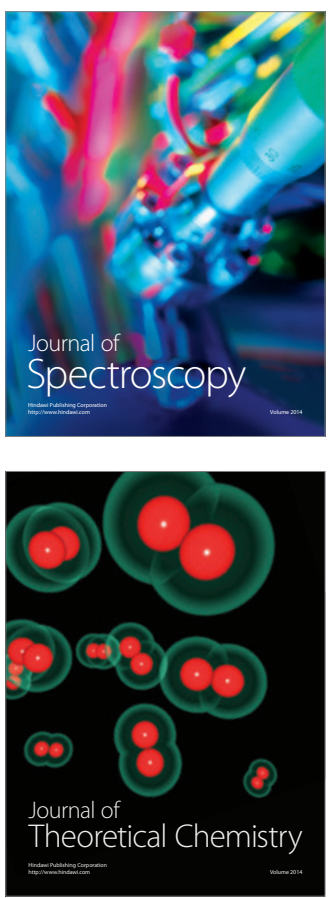
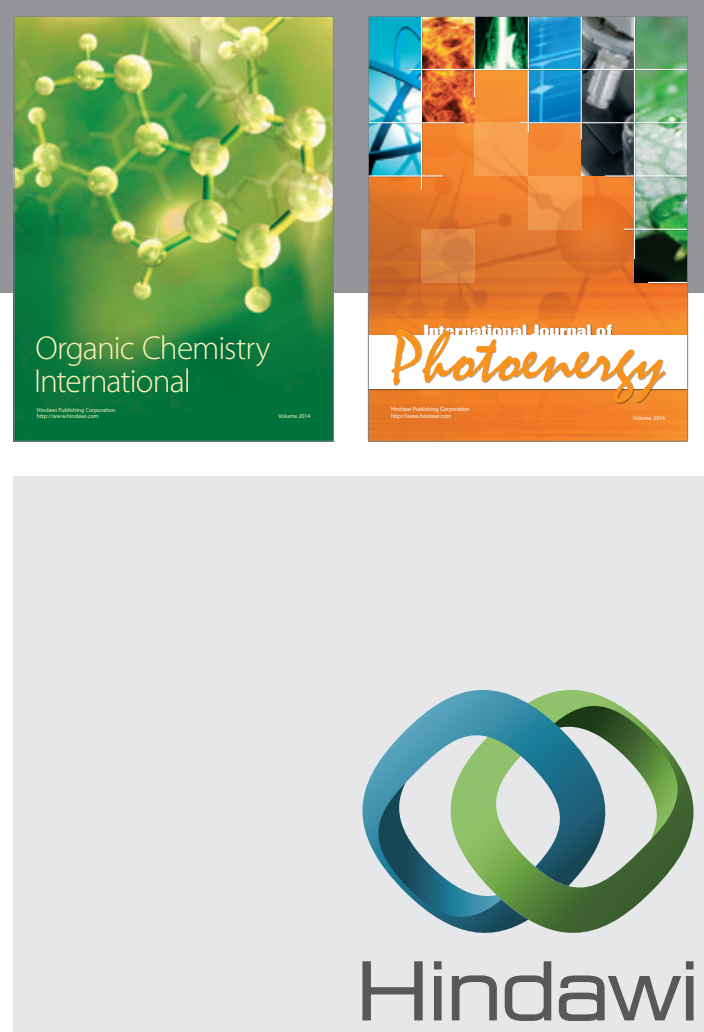

Submit your manuscripts at

http://www.hindawi.com

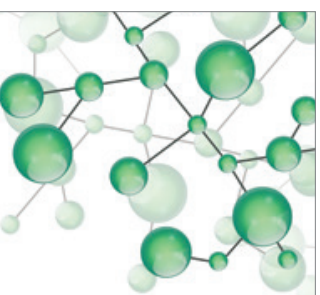

International Journal of

Inorganic Chemistry

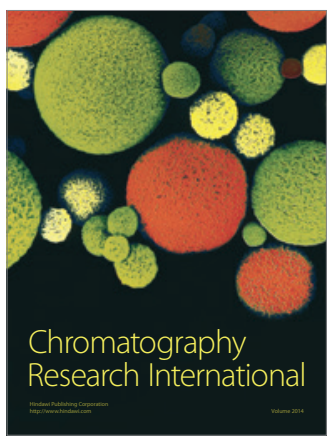

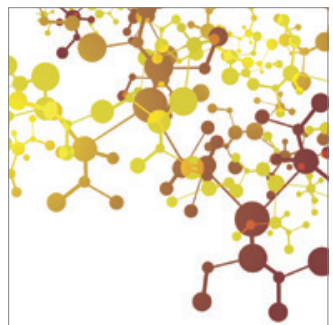

Applied Chemistry
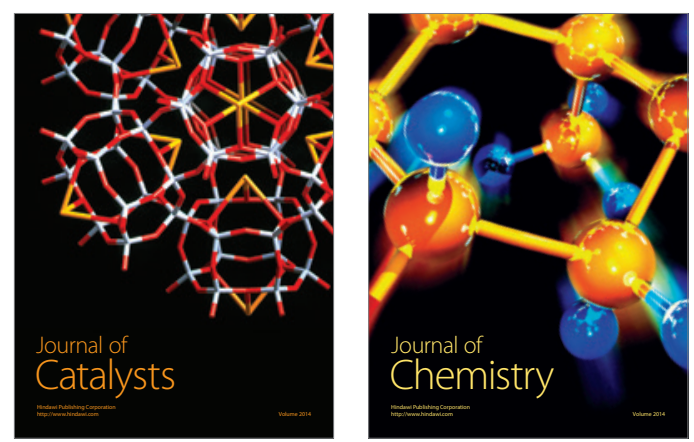
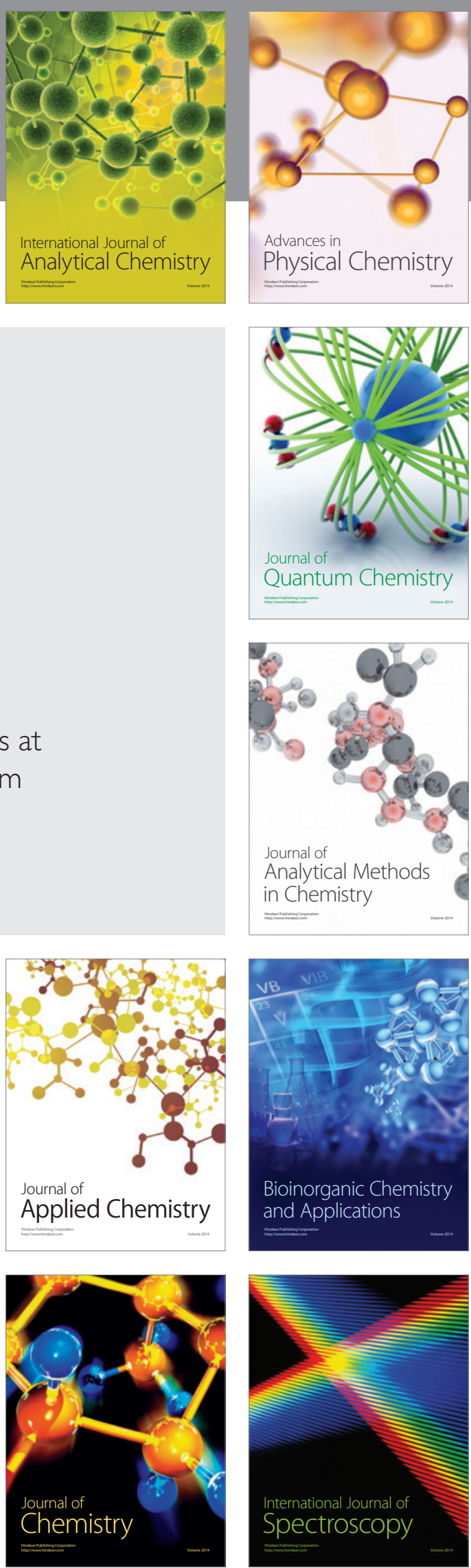